\title{
Editorial
}

\section{Tiempo de bienales}

\author{
Nieto Fernández, Enrique \\ Universidad de Alicante, Dpto. de Expresión Gráfica y Cartografía, enrique.nieto@ua.es \\ Director [i2]
}

Mientras este nuevo número de la revista [i2] sale a las ondas, la XVI Bienal de Arquitectura de Venecia está teniendo lugar. Revistas y bienales constituyen artefactos donde la arquitectura se enacta y se socializa, lugares para la repetición y la diferencia. Allí se debate y se sanciona, también se adquiere visibilidad y se encuentran canales de comunicación. Este tipo de asuntos tan propios de cualquier campo del saber, de cualquier conjunto de prácticas, no deben pasar inobservados. La Bienal de Venecia ocurre cada dos años, y en ese espaciado de sus tiempos reside su interés. Las revistas son más continuas y hacen un trabajo de fondo. Ambas requieren de un trabajo de edición para filtrar lo que ocurre y legitimar así ciertas presencias y no otras. También tenemos exposiciones, muestras, seminarios, congresos, jornadas, colegios profesionales y escuelas de arquitectura. Lugares, tiempos y procedimientos que atraviesan los distintos conjuntos de prácticas y nos atraviesan a nosotrxs.

La Bienal de Venecia de este año deja un regusto extraño. Asistimos a las jornadas de inauguración, el ambiente era festivo, son momentos para el reencuentro. También para todo tipo de sociopatías. La propuesta de Yvonne Farrell y Shelley McNamara, titulada FREESPACE, aspiraba a someter a escrutinio público ejemplos, propuestas o elementos que ejemplificaran cualidades esenciales de la arquitectura, lo que podría incluir desde la modulación, riqueza y materialidad de las superficies hasta la orquestación y secuenciado de movimientos, revelando de esta manera el poder encarnado y la belleza de la arquitectura. Si el enunciado era ya confuso, la falta de una edición decidida de los contenidos nos alejaba aún más de una percepción diferencial de las prácticas allí referenciadas. O mejor dicho, las producciones. Por allí encontramos entremezclados proyectos de gran interés y presencias rutinarias, pocas sorpresas en los pabellones principales. Pasamos de la poderosa sensorialidad de las maquetas de Peter Zumthor a presencias tan extrañas como la ampliación del Ayuntamiento de Murcia de Rafael Moneo, acabada ya hace 20 años o la torre Cube en Guadalajara, de Carmen Pinós, finalizada en 2005.

Los pabellones nacionales, sin embargo, me interesaron más. Por su pequeño tamaño, a menudo son lugares donde de manera más decidida se apuesta por un camino particular. También es el lugar donde se reproducen los grandes mitos fundacionales. Alemania hace presente su poderío inversor y su capacidad de regeneración urbana, Israel insiste en presentarse como un estado pacificador y mediador, Estados Unidos se propone como punto de paso entre lo 
local y lo global, con gran atención por el carácter transnacional de los conflictos, Chile insiste en hacer aflorar su problemática hisoria y Suiza... Suiza recibe el premio al mejor pabellón.

El pabellón de España, comisariado por Atxu Aman, abordó una de las cuestiones más relevantes de la arquitectura española, las producciones originadas en las escuelas de arquitectura, ese trabajo injustamente segmentado de los entornos profesionales y que sin embargo dice tanto de lo que somos. Las escuelas de arquitectura son auténticas fábricas de subjetividad, nuestras prácticas docentes son prácticas arquitectónicas de pleno derecho, en las escuelas reside la capacidad, maquínica y reproductiva, de la arquitectura. Y por eso conviene prestarles atención. El pabellón aparecía completamente recubierto de trabajos de estudiantes y textos de algunxs invitadxs que organizaban someramente los contenidos. De manera paralela, una web daba cuenta de un inventario aún mayor de trabajos. Valoramos positivamente este esfuerzo por dignificar ese trabajo continuo que sucede en las instituciones, por hacer visible la condición política de la Universidad y por reivindicar el trabajo de los estudiantes. El trabajo de Atxu destaca por su esfuerzo para que la Universidad merece la pena, por reclamar su centralidad, por su obsesión por destacar la dimensión fundante del trabajo de lxs estudiantes, por intentar obstinadamente borrar ese límite irreal entre el tiempo de la Universidad y el tiempo de la profesión, desplazando así el foco a la subjetividad itinerantes de lxs arquitectxs, un becoming siempre deseoso y tan conectado con algunas sensibilidades contemporáneas.

Queda siempre el sueño borgiano de hacer presente todo lo que hay, de que estén todos los que son. Mientras se dilata en el tiempo el cumplimiento de este delirio, queda la edición de nuestros asuntos como cuestión principal. Reivindicar así el papel de lxs comisarixs, puntuar los asuntos que son pertinentes en cada caso, hacer visibles prácticas de interés. Asumir ese riesgo no es tarea fácil ante la urgencia de un proyecto de ejecución encima de la mesa. Para nosotrxs y desde [i2], se nos antoja imprescindible reivindicar estas maneras otras de hacer arquitectura. Y apostar por ellas.

Mientras tanto, ¿Qué hacer con nuestras revistas? Más allá de ser carne de doctorandxs enloquecidxs por encontrar acomodo, ¿qué papel pueden jugar revistas como la nuestra, en un tiempo digital postpapel? Nosotros hemos comenzado el camino de las secciones monográficas vinculadas a proyectos de investigación y a mejorar la diversidad de secciones. También aparece ahora una primera versión de una posible red de revistas científicas de arquitectura en España. Pequeños visores para pensarnos en comunidad. 
